\title{
In vitro effectiveness of Brazilian brown propolis against Enterococcus faecalis
}

\begin{abstract}
Hévelin Couto PIMENTA ${ }^{(a)}$ Ivana Maria Povoa VIOLANTE(b) Carlo Ralph de MUSIS(c) Álvaro Henrique BORGES(a) Andreza Maria Fábio ARANHA ${ }^{(a)}$
\end{abstract}

(a) University of Cuiabá, School of Dentistry, Dental Sciences, Cuiabá, MT, Brazil.

(b) University of Cuiabá, School of Pharmacy-Biochemistry, Department of Pharmacognosy, Cuiabá, MT, Brazil.

(c) University of Cuiabá, School of Dentistry, Environmental Sciences, Cuiabá, MT, Brazil.

Declaration of Interests: The authors certify that they have no commercial or associative interest that represents a conflict of interest in connection with the manuscript.

Corresponding Author:

Andreza Maria Fábio Aranha

E-mail: andreza.aranha@gmail.com

DOI: 10.1590/1807-3107BOR-2015.vol29.0058

Submitted: Sep 14, 2014

Accepted for publication: Jan 16, 2015

Last revision: Apr 08, 2015
Abstract: The aim of this study was to evaluate the in vitro antimicrobial activity of Brazilian brown propolis as an intracanal medication against Enterococcus faecalis. Thirty dentin discs prepared from intact freshly extracted bovine maxillary central incisors were infected with E. faecalis for 21 days. The specimens were distributed into six groups according to the medicament used as follows: G1- calcium hydroxide paste; G2- Carbowax 400 (control group); G3- 20\% brown propolis paste; G4- 40\% brown propolis paste; G5- 20\% brown propolis paste + calcium hydroxide paste; and G6- $40 \%$ brown propolis paste + calcium hydroxide paste. The experimental pastes were placed into the canal lumen and left for 14 days. After each period, irrigation was performed with sterile saline to remove the medicament, and the canals were dried with sterile paper points. The dentin chips were removed from the canals with sequential sterile round burs at low speed and were immediately collected in separate test tubes containing BHI broth. The tubes were incubated at $37^{\circ} \mathrm{C}$, and microbial growth was analyzed by spectrophotometry after 15 days. All the experimental medications significantly reduced the number of viable bacteria. The G4 and G5 pastes were more effective than the G1 paste, with $35.8 \%$, $41 \%$, and $21.3 \%$ antibacterial activity, respectively. Brazilian brown propolis shows antibacterial capacity against $E$. faecalis.

Keywords: Anti-Infective Agents; Propolis; Enterococcus faecalis.

\section{Introduction}

Approximately 700 species of microorganisms comprise the oral microflora, many of which are closely associated with the development of periapical lesions. ${ }^{1}$ Endodontic infections are considered polymicrobial, ${ }^{2}$ and Enterococcus faecalis is a gram-positive, facultative anaerobe that is often isolated during root canals with dental pulp necrosis and persistent infections after endodontic treatments. ${ }^{2,3}$ This microorganism is able to penetrate deep into the dentinal tubules and is difficult to eliminate after biomechanical treatment. ${ }^{3}$ E. faecalis is considered a persistent endodontic pathogen, ${ }^{4}$ which makes its control and elimination a challenge for the success of endodontic treatment.

Sanitizing infected root canals through biomechanical treatment and auxiliary agents in order to eliminate bacterial contamination and prevent reinfection has been a challenge for endodontics. ${ }^{5}$ Biomechanical treatment of root canals significantly reduces microbial organisms in the endodontic 
microbiota, ${ }^{6}$ but it is unable to completely disinfect some areas due to anatomical complexities, causing persistent microorganisms to survive, multiply, and reinfect the pulp space. ${ }^{7}$ Calcium hydroxide has been the most used intracanal medication due to its antimicrobial properties, promotion of a temporary physical sealing of the root canal, and osteogenic potential. ${ }^{8}$ However, there is evidence of resistance to this medication by E. faecalis. ${ }^{3}$ Because there are limitations to the complete removal of endodontic biofilms by conventional biomechanical treatment techniques, the search for alternative substances that are effective against resistant pathogens, such as E. faecalis, is growing. ${ }^{4}$

Propolis is a resinous product containing secretions from bees and plant resins, whose composition depends on the regional climate, flora, and time of year in which it is collected. ${ }^{9}$ There are different types of propolis that are characterized and classified according to their chemical composition. ${ }^{9}$ More than 300 components have been identified, including phenolic compounds, such as flavonoids, phenolic acids, and phenolic acid esters, the main components of propolis from temperate regions..$^{10}$ Among tropical countries, Brazil has the highest chemical diversity of propolis types, such as those that contain phenylpropanoids, prenylated phenylpropanoids (e.g., artepillin C), and sesqui- and diterpenoids, ${ }^{11}$ which confer immunostimulatory, antioxidant, anti-inflammatory, and antimicrobial properties, respectively. ${ }^{12}$

Studies have shown the potential of propolis against resistant microorganisms. ${ }^{13,14,15}$ Thus, this study aimed to investigate the potential antimicrobial activity of brown propolis from the Brazilian Cerrado with or without calcium hydroxide paste as an intracanal medication against $E$. faecalis.

\section{Methodology Obtaining the crude brown propolis extract}

Brown propolis was collected in the Cerrado region of the state of Mato Grosso, the second largest biome in Brazil, situated at $19^{\circ} 40^{\prime}$ of south latitude, where the annual average temperature is $24^{\circ} \mathrm{C}$. The crude ethanolic extract of propolis was obtained by extraction in $80 \%$ cereal alcohol at $60^{\circ} \mathrm{C}$ and subsequent concentration in a rotaevaporator (Rotary evaporator 802, Fisatom, São Paulo, Brazil). ${ }^{16}$

\section{Minimum inhibitory concentration (MIC)}

To determine the MIC of the ethanolic extract of brown propolis, a broth microdilution was performed. The extract was serially solubilized in dimethyl sulfoxide (DMSO) ${ }^{16}$ at concentrations of $20 \mathrm{mg} / \mathrm{mL}$, $50 \mathrm{mg} / \mathrm{mL}, 100 \mathrm{mg} / \mathrm{mL}$, and $200 \mathrm{mg} / \mathrm{mL}$. Four to five 24-hour colonies of $E$. faecalis were selected (ATCC 29212) and grown in Muller-Hinton Broth (Difco Laboratories, Mogi das Cruzes, São Paulo, Brazil). The turbidity of the cell suspension was adjusted to obtain approximately $1.5 \times 10^{8}$ cells $/ \mathrm{mL}$ and then diluted to obtain the inoculum at a concentration of $10^{7}$ cells $/ \mathrm{mL}$. Chloramphenicol was used as a standard. The resazurin technique was conducted to assess cell viability. ${ }^{16}$ Each concentration of the extract was assayed in duplicate, and the test was repeated three times. The MIC of brown propolis against $E$. faecalis was $1000 \mathrm{mg} / \mathrm{mL}$.

\section{Intracanal medications}

For the preparation of the experimental pastes, the following were used: high-purity calcium hydroxide (Hidroxil, Inodon, Porto Alegre, Brazil), polyethylene glycol (Carbowax 400, Henrifarma, São Paulo, Brazil), 20\% brown propolis extract, and 40\% brown propolis extract. The intracanal medications, manipulation ratios, and the groups that represent them are described in Table 1 . The $\mathrm{pH}$ values of the brown propolis and calcium hydroxide pastes, alone and combined, were measured by a digital $\mathrm{pH}$ meter.

\section{Preparation of root dentin blocks}

The dentin block model used in this study was modified from Gomes et al. ${ }^{17}$ Briefly, 30 intact freshly extracted bovine maxillary central incisors with complete root formations were selected. After being cleaned, they had their surfaces disinfected and preserved in $0.1 \%$ thymol solution under refrigeration until specimen preparation. Root segments with a length of $4 \mathrm{~mm}$ were prepared by cutting off the apical $5 \mathrm{~mm}$ and coronal two-thirds. Each $18 \mathrm{~mm}$-long specimen with a central pulp space was divided into three blocks. Only the middle segments that had 
Table 1. Descriptive analysis of the bacterial growth rate based on the variable intracanal medication.

\begin{tabular}{lcccc}
\hline Intracanal medication* & Number of samples & $\begin{array}{c}\text { Mean minimum absorbance } \\
(570 \mathrm{~nm})\end{array}$ & $\begin{array}{c}\text { Mean maximum absorbance } \\
(630 \mathrm{~nm})\end{array}$ & $\begin{array}{c}\text { Mean bacterial growth rate } \\
(\%)\end{array}$ \\
\hline G1 & 24 & 0.61 & 0.28 & -21.35 \\
G2 & 30 & 0.45 & 0.15 & 3.66 \\
G3 & 29 & 0.61 & 0.30 & -34.59 \\
G4 & 24 & 0.67 & 0.30 & -35.82 \\
G5 & 30 & 0.71 & 0.35 & -41.05 \\
G6 & 30 & 0.50 & 0.23 & -29.83 \\
\hline
\end{tabular}

* G1- base paste; G2- Carbowax 400; G3- 20\% brown propolis paste; G3- 40\% brown propolis paste; G5- 20\% brown propolis paste + base paste; G6- 40\% brown propolis paste + base paste.

an external diameter of approximately $6 \mathrm{~mm}$ were used. The root cementum was removed, and the root canals were enlarged by using carbide round burs with a 2.1 mm diameter (Dentsply, Petrópolis, Brazil). Organic and inorganic debris and the smear layer were removed. The specimens were individually placed in bijoux bottles containing $3.0 \mathrm{~mL}$ BHI and autoclaved for 15 minutes at $121^{\circ} \mathrm{C}$. Sterility was checked by incubating the bijoux bottles for 24 hours at $37^{\circ} \mathrm{C}$.

\section{Inoculation and disinfection of the dentin specimens}

Isolated 24-hour colonies of pure Enterococcus faecalis cultures (ATCC 29212) grown on $5 \%$ defibrinated sheep blood-BHI agar plates were suspended in $5 \mathrm{~mL}$ of sterile Brain Heart Infusion broth (BHI; Difco Laboratories, Mogi das Cruzes, São Paulo, Brazil) and adjusted to approximately $1.5 \times 10^{8} \mathrm{CFU} \mathrm{mL} \mathrm{mL}^{-1}$. Two milliliters of sterile BHI was replaced by the bacterial inoculum. The specimens were kept at $37^{\circ} \mathrm{C}$ for 21 days, and $1 \mathrm{~mL}$ of contaminated $\mathrm{BHI}$ was replaced by freshly prepared BHI every 2 days to avoid medium saturation. The turbidity of the medium during the incubation period indicated bacterial growth. The purity of the cultures was confirmed by Gram staining and colony morphology on BHI agar blood.

After the infection period, the specimen canals were irrigated with $5 \mathrm{~mL}$ of $0.9 \%$ sterile saline and dried with sterile paper points. The outer specimen surfaces were covered with nail varnish to prevent contact of the medicament with the external surface. The dentin blocks were fixed at the bottom of the wells in 24-well cell culture plates (Corning, Hexis Científica, Jundiaí, Brazil) with decontaminated sticky wax, which also obliterated the apical surface of the root canal.
The wells were then filled with agar at $46^{\circ} \mathrm{C}$ until it reached the upper surface of the dentin specimens. The intracanal medications were applied to the canal lumen until the canals were completely full. The 30 dentin blocks were divided into six groups according to the experimental paste used as follows ( $\mathrm{N}=5$ /group): G1: Calcium hydroxide paste (high-purity calcium hydroxide + Carbowax 400; 4 g/4.5 mL); G2: Carbowax 400 (negative control); G3: 20\% crude brown propolis extract + Carbowax 400 (0.2 g/mL); G4: 40\% crude propolis extract + Carbowax $400(0.4 \mathrm{~g} / \mathrm{mL}) ; \mathrm{G} 5: 20 \%$ crude propolis extract + calcium hydroxide paste (1:1); and G6: $40 \%$ crude propolis extract + calcium hydroxide paste (1:1). Finally, the specimens were incubated at $37^{\circ} \mathrm{C}$ for 14 days.

After the experimental period, the medicament was washed with sterile saline. Dentin shavings from the internal surface of the canal were obtained with spherical drills with progressive diameter numbers 6 and 8 (Dentsply, Petrópolis, Brazil) at a low speed, allowing the evaluation of the medication diffusion within the dentin structure. The dentin shavings within each drill bit and the remainder of the specimens were incubated in $3 \mathrm{~mL}$ of $\mathrm{BHI}$ broth at $37^{\circ} \mathrm{C}$ for 15 days. ${ }^{17}$ The tubes were evaluated daily to verify the turbidity of the broth and to identify indications of bacterial growth. At the end of the experimental period, bacterial growth was analyzed by spectrophotometry (ELISA reader, SpectraMax 190 Absorbance Microplate Reader, Sunnyvale, USA) at wavelengths of $570 \mathrm{~nm}$ (reduction) and $630 \mathrm{~nm}$ (oxidation). For this purpose, $100 \mu \mathrm{L}$ from the contents of each tube was transferred in triplicate to 96 -well cell culture plates. Thirty microliters of $0.01 \%$ resazurin aqueous solution was added, and 
the plates were incubated at $37^{\circ} \mathrm{C}$ for 4 hours. The bacterial growth rate was calculated according to the formula developed by Szliszka et al. . $^{16}$

\section{Statistical analysis}

The statistical one-way ANOVA and Tamhane posthoc tests were performed to compare the different intracanal medications. To evaluate the correlation between the $\mathrm{pH}$ values and the bacterial growth rate, the Pearson correlation test was applied. The significance was established at a 5\% level $(p<0.05)$.

\section{Results}

The average $\mathrm{pH}$ values of the medications tested for groups G1 to G6 were 13.1, 9.5, 6.8, 5.8, 11.8, and 12.6 , respectively, which showed no correlation with bacterial growth $(\mathrm{p}=0.758)$.

Bacterial growth was only associated with the intracanal medication $(\mathrm{p}=0.000)$ and not with the diffusion of the pastes within the dentin $(p=0.174)$, evaluated by the different bur sizes or the combination of both $(p=0.705)$. All the experimental pastes showed bacterial growth inhibition, with the exception of the negative control group (G2), confirming the efficacy of the methodology (Table 1). However, the $20 \%$ brown propolis paste associated with calcium hydroxide and the $40 \%$ brown propolis paste exhibited better results against E. faecalis, compared with the calcium hydroxide paste (Figure 1). Moreover, the calcium hydroxide paste showed similar results to the $20 \%$ brown propolis paste

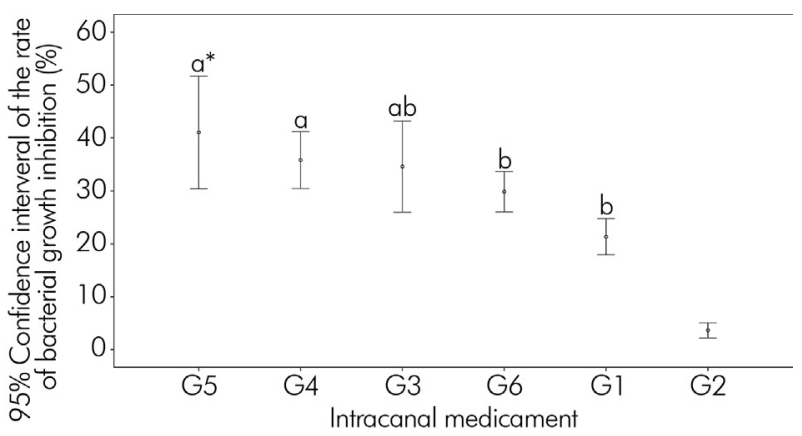

*Identical letters represent statistically equal values.

Figure 1. Graphical representation of the $95 \%$ confidence intervals for growth rate inhibition according to the tested intracanal medications. and the $40 \%$ brown propolis paste associated with calcium hydroxide (Figure 1).

\section{Discussion}

Several methods have been proposed to evaluate the potential antimicrobial activity of intracanal medications for treating endodontic infections, such as the agar diffusion test, ${ }^{5}$ the broth microdilution test $\mathrm{t}^{13,18}$ and the dentin infection and disinfection tests. ${ }^{14,15,17,18,19}$

In this study, broth microdilution was conducted to determine the MIC of brown propolis against E. faecalis, which was $1000 \mathrm{mg} / \mathrm{mL}$. By contrast, lower MIC values against $E$. faecalis were observed for other types of propolis, such as $4 \mathrm{mg} / \mathrm{mL}$ of the Turkey TB propolis,$^{20} 340 \mathrm{mg} / \mathrm{mL}$ of the Iran propolis, ${ }^{19}$ and higher values of $6,425 \mathrm{mg} / \mathrm{mL}$ for the propolis from southern Brazil. ${ }^{21}$ In addition, different MIC values were observed for Brazilian green propolis against several microorganisms, including Peptostreptococcus anaerobius $(20.8 \mathrm{mg} / \mathrm{mL})$, Porphyromonas gingivalis (294.4 mg/mL), Fusobacterium nucleatum ( $256 \mathrm{mg} / \mathrm{mL}$ ), and Prevotella melaninogenica $(204.8 \mathrm{mg} / \mathrm{mL}) .{ }^{22}$ There is evidence that the differences in antimicrobial activity depend on the bacterial strains involved and the composition of the propolis extracts, ${ }^{23}$ which our group is already researching.

The infection and disinfection tests of bovine dentin were conducted using E. faecalis (ATCC 29212) to evaluate the antimicrobial potential of brown propolis; this bacterium has been extensively investigated ${ }^{14,15,21}$ because it is often isolated in root canals with persistent infections. ${ }^{18}$ There is evidence that the presence of E. faecalis in teeth with filled canals, cases of chronic apical periodontitis, ${ }^{24}$ and infections after endodontic treatments are due to its high resistance to antimicrobials, ${ }^{3,21}$ its survival for long periods in environments deprived of nutrients and oxygen, ${ }^{24}$ and its high virulence. These characteristics of E. faecalis are likely a result of its production of aggregation substances, surface adhesins, extracellular superoxide, lytic enzyme gelatinase, and hyaluronidase. ${ }^{25}$ In the present study, the period of bovine dentin contamination was 21 days, which was confirmed previously by electron scanning microscopy. ${ }^{13}$

Bovine teeth were used in this research because they are easy to obtain and handle. ${ }^{17}$ Additionally, the 
structure of the bovine dentin resembles the human dentin with respect to quantity, size, shape, diameter, and density of the dentinal tubules, which enables the use of bovine dentin in methods evaluating antimicrobial agents. ${ }^{18}$

To overcome the difficulty of controlling endodontic biofilms with biomechanical preparations of the root canal system, irrigation agents and intracanal medications should be chosen based on their biocompatibility with periapical tissues and their efficacy against resistant pathogens. The use of propolis has been encouraged due to its therapeutic properties, including antimicrobial activity against endodontic pathogens. ${ }^{13,14,15,19}$ The biological activities of propolis are mainly related to the presence of phenols and polyphenols, which are aromatic substances that derive flavones, flavonoids, and flavonols and are active against the bacterial cell wall. ${ }^{25}$

There is no evidence of the optimal concentration of brown propolis against $E$. faecalis. Therefore, based on MIC results and the fact that experimental pastes that may work as a barrier for microorganisms have been applied within bovine dentin, ${ }^{17,18}$ we decided to study the antimicrobial activity of $20 \%$ and $40 \%$ brown propolis extracts.

In the present study, the bacterial growth of $E$. faecalis was inhibited by all the experimental medications. However, the $40 \%$ brown propolis extract (G4) and the $20 \%$ brown propolis extract associated with calcium hydroxide paste (G5) were more effective than calcium hydroxide paste (G1), with bacterial growth inhibitions of $35.8 \%, 41 \%$, and $21.3 \%$, respectively. Although no previous studies have evaluated the antibacterial activity of brown propolis, the greater effectiveness of propolis over calcium hydroxide has been observed in previous studies. . $^{13,14,15,19}$

Calcium hydroxide paste has strong biological and antimicrobial properties due to its highly alkaline $\mathrm{pH}^{8}$ and is considered the gold standard intracanal medication for treating endodontic infections. However, calcium hydroxide has disadvantages, such as its low potential against $E$. faecalis, ${ }^{3,26}$ which can survive in dentin tubules for long periods in the presence of the antimicrobial agent. ${ }^{18,26}$ Thus, in this study, the brown propolis extracts were mixed with calcium hydroxide to observe a possible improvement of the calcium hydroxide paste against $E$. faecalis.

All medications based on the tested brown propolis showed antimicrobial activity against $E$. faecalis, which is in agreement with previous studies ${ }^{13,14,19,27}$ and with the fact that propolis exhibits significant antimicrobial activity against the more resistant, gram-positive facultative and strictly anaerobic species. ${ }^{27}$ The $20 \%$ crude propolis extract associated with calcium hydroxide paste exhibited an antimicrobial activity similar to the $40 \%$ crude propolis extract associated with calcium hydroxide paste, but it performed better than the isolated calcium hydroxide. Because there are no previous studies regarding the association between calcium hydroxide paste and crude propolis extracts at different concentrations, this result indicates the need for further investigation into the isolation and identification of brown propolis components. Furthermore, future studies will help to explain the synergy between the calcium hydroxide components and the propolis components, which is of fundamental importance for determining the antimicrobial potential of propolis. ${ }^{14}$

In this investigation, the average $\mathrm{pH}$ of the $20 \%$ and $40 \%$ propolis pastes was 6.8 and 5.8 , respectively. Most bacteria present in endodontic infections show growth at a $\mathrm{pH}$ between 6.5 and 7.5, and only a few microorganisms thrive at higher $\mathrm{pH}$ values, ${ }^{18}$ such as E. faecalis, which is capable of growing in an alkaline $\mathrm{pH}$ exceeding $11.5 .{ }^{4}$ In agreement with a previous study, ${ }^{28}$ the association of the $20 \%$ and $40 \%$ propolis pastes with calcium hydroxide resulted in a $\mathrm{pH}$ increase from 6.8 and 5.8 to 11.8 and 12.6, respectively. However, in this study, the $\mathrm{pH}$ did not affect the antimicrobial activity of the intracanal medications studied.

Finally, further investigations are necessary to evaluate biocompatibility with periapical tissues, to isolate and identify the components of brown propolis, and to analyze the synergism between the components of propolis and calcium hydroxide.

\section{Conclusion}

The present study demonstrated that, although medications based on brown propolis with or without calcium hydroxide have limitations inherent to an in vitro study, they are effective against $E$. faecalis. 


\section{References}

1. Kakehashi S, Stanley HR, Fitzgerald RJ. The effects of surgical exposure of dental pulps in germ-free in conventional laboratory rats. Oral Surg Oral Med Oral Pathol. 1965 Sep;20:340-9.

2. Sunde PT, Olsen I, Debelian GJ, Tronstad L. Microbiota of periapical lesions refractory to endodontic therapy. J Endod. 2002 Apr;28(4):304-10.

3. Love RM. Enterococcus faecalis-a mechanism for its role in endodontic failure. Int Endod J. 2001 Jul;34(5):399-405.

4. Donlan RM, Costerton JW. Biofilms: survival mechanism of clinically relevant microorganisms. Clin Microbiol Rev. 2002 Apr;15(2):167-93.

5. Poggio C, Colombo M, Scribante A, Sforza D, Bianchi S. In vitro antibacterial activity of different endodontic irrigants. Dent Traumatol. 2012 Jun;28(3):205-9.

6. Peters LB, Wesselink PR, van Winkelhoff AJ. Combinations of bacterial species in endodontic infections. Int Endod J. 2002 Aug;35(8):698-702.

7. Siqueira Júnior JF, Lopes HP. Mechanisms of antimicrobial activity of calcium hydroxide: a critical review. Int Endod J. 1999 Sep;32(5):361-9.

8. Estrela C, Pimenta FC, Ito IY, Bammann LL. Antimicrobial evaluation of calcium hydroxide in infected dentinal tubules. J Endod.1999 Jun;25(6):416-8.

9. Salatino A, Fernandes-Silva CC, Righi AA, Salatino ML. Propolis research and the chemistry of plant products. Nat Prod Rep. 2011 May;28(5):925-36.

10. Hayacibara MF, Koo H, Rosalen PL, Duarte S, Franco EM, Bowen $\mathrm{WH}$, et al. In vitro and in vivo effects of isolated fractions of Brazilian propolis on caries development. J Ethnopharmacol. 2005 Oct 3;101(1-3):110-5.

11. Teixeira EW, Message D, Negri G, Salatino A, Stringheta PC. Seasonal variation, chemical composition and antioxidant activity of Brazilian propolis samples. Evid Based Complement Alternat Med. 2010 Sep;7(3):307-15.

12. Sforcin JM, Fernandes Júnior A, Lopes CA, Bankova V, Funari SR. Seasonal effect on Brazilian propolis antibacterial activity. J Ethnopharmacol. 2000 Nov;73(1-2):243-9.

13. Awawdeh L, Al-Beitawi M, Hammad M. Effectiveness of propolis and calcium hydroxide as a short-term intracanal medicament against Enterococcus faecalis: a laboratory study. Aust Endod J. 2009 Aug;35(2):52-8.

14. Kayaoglu G, Omurlu H, Akca G, Gurel M, Gençay O, Sorkun $\mathrm{K}$, et al. Antibacterial activity of Propolis versus conventional endodontic disinfectants against Enterococcus faecalis in infected dentinal tubules. J Endod. 2011 Mar;37(3):376-81.

15. Madhubala MM, Srinivasan N, Ahamed S. Comparative evaluation of propolis and triantibiotic mixture as an intracanal medicament against Enterococcus faecalis. J Endod. 2011 Sep;37(9):1287-9.
16. Szliszka E, Zydowicz G, Janoszka B, Dobosz C, KowalczykZiomek G, Krol W. Ethanolic extract of Brazilian green propolis sensitizes prostate cancer cells to TRAIL-induced apoptosis. Int J Oncol. 2011 Apr;38(4):941-53.

17. Gomes BP, Souza SF, Ferraz CC, Teixeira FB, Zaia AA, Valdrighi L, et al. Effectiveness of $2 \%$ chlorhexidine gel and calcium hydroxide against Enterococcus faecalis in bovine root dentine in vitro. Int Endod J. 2003 Apr;36(4):267-75.

18. Haapasalo $M$, Orstavik D. In vitro infection and disinfection of dentinal tubules. J Dent Res. 1987 Aug;66(8):1375-9.

19. Zare Jahromi M, Toubayani H, Rezaei M. Propolis: a new alternative for root canal disinfection. Iran Endod J. 2012 Summer;7(3):127-33.

20. Uzel A, Sorkun K, Oncag O, Cogulu D, Gencay O, Salih B. Chemical compositions and antimicrobial activities of four different Anatolian propolis samples. Microbiol Res. 2005;160(2):189-95.

21. Ferreira FB, Torres SA, Rosa OP, Ferreira CM, Garcia RB, Marcucci MC, et al. Antimicrobial effect of propolis and other substances against selected endodontic pathogens. Oral Surg Oral Med Oral Pathol Oral Radiol Endod. 2007 Nov;104(5):709-16.

22. Koru O, Toksoy F, Acikel CH, Tunca YM, Baysallar M, Uskudar Guclu A, et al. In vitro antimicrobial activity of propolis samples from different geographical origins against certain oral pathogens. Anaerobe. 2007 Jun-Aug;13(3-4):140-5.

23. Barbaric M, Miskovic K, Bojic M, Loncar MB, Smolcic-Bubalo A, et al. Chemical composition of the ethanolic propolis extracts and its effect on HeLa cells. J Ethnopharmacol. 2011 Jun 1;135(3):772-8.

24. Kayaoglu G, Orstavik D. Virulence factors of Enterococcus faecalis: relationship to endodontic disease. Crit Rev Oral Biol Med. 2004 Sep;15(5):308-20.

25. Bankova VS, Castro SL, Marcucci MC. Propolis: recent advances in chemistry and plant origin. Apidologie. 2000 Sep;31(1):3-15.

26. Lima RK, Guerreiro-Tanomaru JM, Faria-Júnior NB, Tanomaru-Filho M. Effectiveness of calcium hydroxide-based intracanal medicaments against Enterococcus faecalis. Int Endod J. 2012 Apr;45(4):311-6.

27. Koo H, Gomes BP, Rosalen PL, Ambrosano GM, Park YK, Cury JA. In vitro antimicrobial activity of propolis and Arnica montana against oral pathogens. Arch Oral Biol. 2000 Feb;45(2):141-8.

28. Monteiro MC, Cruz M, Cantizani J, Moreno C, Tormo JR, Mellado E, et al. A new approach to drug discovery: high-throughput screening of microbial natural extracts against Aspergillus fumigatus using resazurin. J Biomol Screen. 2012 Apr;17(4):542-9. 